\title{
Brillouin Scattering Study of Binary Potassium Germanate Glasses
}

Seiichi Mamiya*, Yu Matsuda, Kazuhiro Kaneda, Mitsuru Kawashima, and Seiji Kojima Graduate School of Pure and Applied Sciences, University of Tsukuba, Ibaraki 305-8573, JAPAN e-mail: mamiya@ims.tsukuba.ac.jp

\begin{abstract}
The glass samples were prepared in the series $x \mathrm{~K}_{2} \mathrm{O}-(100-x) \mathrm{GeO}_{2}$ with $0<x<27.0$, where $x$ denotes the $\mathrm{K}_{2} \mathrm{O}$ mol\%, by the solution method with high homogeneity. Brillouin spectroscopy has been performed for potassium germanate glasses with increasing alkali contents. The sound velocities and the elastic moduli were measured by Brillouin scattering in $90^{\circ} \mathrm{A}$ scattering geometry. Acoustic velocities for both longitudinal and transverse wave, Debye velocity, elastic moduli and Debye temperatures have been determined with all $\mathrm{K}_{2} \mathrm{O}$ mol\% contents. Each property shows its maximum at about 15 mol\% $\mathrm{K}_{2} \mathrm{O}$ content. This indicates that about 15 mol\% $\mathrm{K}_{2} \mathrm{O}$ content provides the maximum sound velocity. It has been found that the glass transition temperatures are related to the Debye temperatures.
\end{abstract}

Key words: Brillouin scattering, potassium germanate glasses, germanate anomaly, elastic moduli, sound velocity.

\section{Introduction}

Recently Brillouin scattering has been performed for various optical glass devices to investigate their properties for instance acoustic velocities both longitudinal and transverse wave and elastic moduli. There are a lot of studies of Brillouin scattering on 
alkali borate glasses [1] and alkali silicate glasses [2, 3].

The physical properties show germanate anomaly [4] which means that the property values as the function of alkali contents indicate their maxima about the alkali germanate glasses. The germanate anomaly has been widely studied by Kamitsos et al. [5-7] and Henderson et al. [8-10].

Germanate anomaly of density was first found by Ivanov and Evstropiev in sodium and potassium, and by Murthy and Ip in lithium, rubidium and cesium containing germanate glasses. The anomaly maximum varies the range of alkali oxide from 10 to $20 \mathrm{~mol} \%$.

A lot of physical properties (density, refractive index, micro-hardness, acoustic velocity and elastic moduli) of alkali germanate glasses show this phenomenon although those of alkali silicate glasses don’t show such a phenomenon.

Currently, these are two principal models proposed to explain the germanate anomaly. The most widely accepted was first proposed by Ivanov and Evstropiev and Murthy and Ip. Their model attributes the germanate anomaly to a change in the coordination of G from 4 fold to 6 fold.

Another model was proposed by Henderson and Fleet. They suggested that the anomaly is associated with the longer $\mathrm{T}-\mathrm{O}$ (where $\mathrm{T}$ is the tetrahedral cation) distances of $\mathrm{GeO}_{4}$ tetrahedra (relative to $\mathrm{SiO}_{2}$ ) and the effect these longer distances have on the accommodation of alkali metal cations in the network. In this model the addition of small amounts of alkali-oxide causes formation of three-membered rings of $\mathrm{GeO}_{4}$ tetrahedra in the general vicinity of the alkali metal cations. These small rings create smaller network cavities and subsequent local densification [4].

We have investigated the potassium germanate glasses to clear the mechanism of 
germanate anomaly i.e. acoustic velocity, elastic moduli and Debye temperature using Brillouin spectroscopy in $90^{\circ} \mathrm{A}$ scattering geometry and more experimental results are required. It has been found that the glass transition temperatures relate to the Debye temperatures.

\section{Experimental}

\subsection{Sample preparation}

Five glass samples were prepared in the series $x \mathrm{~K}_{2} \mathrm{O} \cdot(100-x) \mathrm{GeO}_{2}$ with $0<x<$ 27.0 where $x$ indicates mol\% $\mathrm{K}_{2} \mathrm{O}$ content. All the glasses were prepared by the "solution method" [11, 12]. The advantage of this method is that the starting materials can be initially made reacted in an aqueous solution in order to achieve homogeneity. Analytical reagent-grade $\mathrm{KOH} \cdot \mathrm{H}_{2} \mathrm{O}$ and $\mathrm{GeO}_{2}$ were used as the starting materials without further purification. The starting materials were made to react by adding distilled pure water in a Teflon beaker. The beaker containing the solution was then placed in a drying oven at $140{ }^{\circ} \mathrm{C}$ for 7 days. After the complete evaporation of water, a chemically synthesized powder was obtained. This powder was fused in a Pt crucible for 1.5 hours at about 950 to $1100{ }^{\circ} \mathrm{C}$ depending on the composition. The homogenized bubble-free melts were splat-quenched and resulting glasses have been preserved in a desiccator to avoid moisture absorption.

Chemical composition analysis of all the glass samples was performed through the method [13]. The result of it is shown in the table 1.

\subsection{Brillouin spectroscopic measurements}

This system is a Sandercock-type 3+3passes tandem multipass Fabry-Perot 
interferometer (FPI). The Brillouin scattering spectra were measured in $90^{\circ} \mathrm{A}$ scattering geometry. A free spectral range of $25 \mathrm{GHz}$ was applied for measurement, and the scanning range was between $\pm 20 \mathrm{GHz}$ for the acquisition of the Brillouin spectra. An ordinary photon counting system and a multichannel analyzer were used to accumulate the signals. The measurement was carried out at the room temperature. The detailed description of the measurements has been written in [14].

\section{Results and discussion}

The figure 1 shows the content dependence of Brillouin spectra in the potassium germanate glasses $\left(0<x<27 \mathrm{~mol} \% \mathrm{~K}_{2} \mathrm{O}\right)$ in $90^{\circ} \mathrm{A}$ scattering geometry. The right-side and left-side band are a longitudinal acoustic (LA) and transverse acoustic (TA) mode respectively. Both modes are shifted increasing with the $\mathrm{K}_{2} \mathrm{O}$ contents to about 15 mol\% and decreasing with increasing $\mathrm{K}_{2} \mathrm{O}$ contents.

The figure 2 shows the content dependence of the longitudinal $V_{L}$, and transverse velocity $V_{T}$. The $V_{L}, V_{T}$ and Debye velocity $V_{D}$ are represented by the following equations

$$
\begin{aligned}
& V_{L, T}=\frac{\lambda_{0}}{\sqrt{2}} \Delta v_{B 90 A, L, T}, \\
& V_{D}=1 /\left(\frac{2}{3 V_{T}^{3}}+\frac{1}{3 V_{L}^{3}}\right)^{\frac{1}{3}},
\end{aligned}
$$

where $\lambda_{0}$ and $\Delta v_{B 90 A, L, T}$ are the wavelength of the laser $(532 \mathrm{~nm})$ and the Brillouin shift (in GHz), respectively. The sound velocities $V_{L, T}$ are proportion to the Brillouin shift as the equation (1) indicates. Therefore, the maximum value of the sound velocities is both 
at about 15 mol\% $\mathrm{K}_{2} \mathrm{O}$ content. This value 15 mol\% is more than the density maximum at $9 \mathrm{~mol} \% \mathrm{~K}_{2} \mathrm{O}$ content [15]. This indicates the sound velocity does not correspond to the density of the glass.

According to our previous Raman scattering study [16], the $520 \mathrm{~cm}^{-1}$ mode is the symmetric stretching vibration of $\mathrm{Ge}(4)-\mathrm{O}-\mathrm{Ge}(4)$ bridges in the three-memebered ring of $\mathrm{GeO}_{4}$ tetrahedra. Its intensity shows the maximum of the density at about $10 \mathrm{~mol} \%$ $\mathrm{K}_{2} \mathrm{O}$ content as same as the density [5]. The number in the parentheses in $\mathrm{Ge}(4)-\mathrm{O}-\mathrm{Ge}(4)$ indicates the coordination number of a $\mathrm{Ge}$ atom. Since the six-membered rings of $\mathrm{GeO}_{4}$ tetrahedra is converted into three-membered rings of $\mathrm{GeO}_{4}$ tetrahedra with increasing $\mathrm{K}_{2} \mathrm{O}$ content, the density of the glass increases. For further increase of the $\mathrm{K}_{2} \mathrm{O}$ content, the $420 \mathrm{~cm}^{-1}$ mode is disappeared $i$. $e$. the six-membered rings of $\mathrm{GeO}_{4}$ tetrahedra are broken down and changed into the three-membered rings of $\mathrm{GeO}_{4}$ tetrahedra at $10 \mathrm{~mol} \% \mathrm{~K}_{2} \mathrm{O}$ content (relative to 15 mol\% $\mathrm{Na}_{2} \mathrm{O}$ content, 20 mol\% $\mathrm{Li}_{2} \mathrm{O}$ content). That means potassium oxide parts the bonding of the rings most strongly among alkali oxides. Then the $520 \mathrm{~cm}^{-1}$ mode is decreased. Because the three-membered rings of $\mathrm{GeO}_{4}$ tetrahedra are decomposed into the chains of $\mathrm{GeO}_{4}$ tetrahedra by $\mathrm{K}_{2} \mathrm{O}$ content. While the maximum of the sound velocity is about $15 \mathrm{~mol} \%$ $\mathrm{K}_{2} \mathrm{O}$ content, the glass containing a proper ratio of the three-membered rings of $\mathrm{GeO}_{4}$ tetrahedra and the chains of $\mathrm{GeO}_{4}$ tetrahedra vibrates like a deformation vibration. Therefore the sound velocity shows the maximum. This network connectivity is destructed by increasing $\mathrm{K}_{2} \mathrm{O}$ content and the three-memebered rings of $\mathrm{GeO}_{4}$ tetrahedra decrease to the initial situation of the $\mathrm{GeO}_{2}$ glass. At the $\mathrm{K}_{2} \mathrm{O}$ content 20 mol\% the higher coordination of $\mathrm{Ge}$ is decomposed gradually. The $\mathrm{Q}^{3}$ (tetrahedra containing 1 non-bridging oxygen) units begin to increase. The concentration of higher coordination 
$\mathrm{Ge}$ atoms is the maximum at about $20 \mathrm{~mol} \% \mathrm{~K}_{2} \mathrm{O}$ content. The same phenomenon is also shown by the other alkali oxides $\left(\mathrm{Li}_{2} \mathrm{O}, \mathrm{Na}_{2} \mathrm{O}\right)$. Therefore alkali oxide has two effects on the density independently. One is to cut the connection of the rings of $\mathrm{GeO}_{4}$, the other is to change the Ge coordination which changes the radius of Ge ion. Density varies according to the combination with two effects of $\mathrm{K}_{2} \mathrm{O}$ content.

The figure 3 shows the elastic moduli. Each elastic modulus i.e. the longitudinal modulus $L$, shear modulus $G$, Young's modulus $E$, bulk modulus $K$ are represented by the following equations

$$
\begin{aligned}
& L=\rho V_{L}^{2} \\
& G=\rho V_{T}^{2} \\
& E=G(3 L-4 G) /(L-G) \\
& K=L-(4 / 3) G
\end{aligned}
$$

where $\rho$ is the density of glass [14]. All the moduli have the maximum at about 15 mol\% $\mathrm{K}_{2} \mathrm{O}$ content.

The figure 4 shows the content dependence of the Debye temperature $\theta_{D}$. Debye temperature $\theta_{D}$ was calculated by the following equation,

$$
\theta_{D}=\frac{h}{k}\left(\frac{3 \rho N_{A}}{4 \pi M}\right)^{\frac{1}{3}} /\left(\frac{2}{3 V_{T}^{3}}+\frac{1}{3 V_{L}^{3}}\right)^{\frac{1}{3}} \text {, }
$$

where $h, k, N_{A}$ and $M$ are Planck constant, Boltzmann constant, Avogadro's number and mean atomic mass, respectively [17]. The maximum of Debye temperatures ( 325 K) of the potassium germanate glasses are also at about $15 \mathrm{~mol} \% \mathrm{~K}_{2} \mathrm{O}$ content.

Kiczenski et al. show the content dependence of the glass transition temperature $\left(T_{g}\right)$ of the potassium germantate glasses (Fig. 4) [18]. This also indicates the maximum of the glass transition point at about $15 \sim 16.7$ mol\% $\mathrm{K}_{2} \mathrm{O}$ content. We obtained the value of $15 \mathrm{~mol} \%$ is the value of the chemical composition analysis. The content 
dependence of the glass transition points is similar to the content dependence of the Debye temperatures. Figure 4 shows that the glass transition points decrease drastically above $16.7 \mathrm{~mol} \% \mathrm{~K}_{2} \mathrm{O}$ contents.

\section{Conclusion}

The sound velocities and the elastic moduli were measured by Brillouin scattering in a $90^{\circ} \mathrm{A}$ scattering geometry. Debye temperatures were also calculated. The sound velocities, Debye velocity, elastic moduli, Debye temperatures and the glass transition points depend on $\mathrm{K}_{2} \mathrm{O}$ content, and their maximum is about $15 \mathrm{~mol} \% \mathrm{~K}_{2} \mathrm{O}$ content which is a little higher than the density maximum at about $10 \mathrm{~mol}^{\circ} \mathrm{K}_{2} \mathrm{O}$ content. The maximum of the sound velocity, elastic moduli and Debye temperature is at about 15 mol\% $\mathrm{K}_{2} \mathrm{O}$ content. This glass contains a proper ratio of the three-membered rings of $\mathrm{GeO}_{4}$ tetrahedra and the chains of $\mathrm{GeO}_{4}$ tetrahedra. The bonding with them has effective network connectivity. Alkali oxide has two effects on the density independently. One is to cut the rings of $\mathrm{GeO}_{4}$, the other is to change the Ge coordination which changes the radius of Ge ion. Density varies according to the combination with two effects of $\mathrm{K}_{2} \mathrm{O}$ content.

\section{Acknowledgement}

This research was partly supported by the Japan Society for the Promotion of Science (JPSJ), Grant-in-aid for JPSJ Fellow for young scientist 19. 574. 


\section{References}

1. Y. Ike, Y. Matsuda, S. Kojima and M. Kodama., Jpn. J. Appl. Phys. 45, 4474 (2006)

2. V. Martinez, C. Martinet, B. Champagnon, R. Le Parc., J. Non-Cryst. Solids, 345-346, 315. (2004).

3. A. Hushur, S. Kojima, M. Kodama, B. Whittington, M. Olesiak, M. Affatigato and S. A. Feller, Jpn. J. Appl. Phys. 44, 6683 (2005)

4. G. S. Henderson, J. Non-Cryst. Solids, 353, 1695 (2007).

5. Y. D. Yiannopoulos, E. I. Kamitsos, H. Jain, Physics and applications of Non-Crystalline Semiconductors in Optoelectronics, Eds. A. Andriesh \& M. Bertolotti, Kluwer, Dordrecht, 317 (1997).

6. E. I. Kamitsos, Y. D. Yiannopoulos, M. A. Karakassides, G. D. Chrlyssikos, \& H. Jain, J. Phys. Chem., 100, 11755 (1996).

7. Y. D. Yiannopoulos, C. P. E. Varsamis, E. I. Kamitsos, J. Non-Cryst. Solids, 293, 244 (2001).

8. G. S. Henderson, M. E. Fleet, J. Non-Cryst. Solids, 134, 259 (1991).

9. H. M. Wang, G. S. Henderson, Chem. Geol., 213, 17 (2004).

10. L. G. Soltay, \& G. S.Henderson, Phys. Chem. Glasses, 46, 381 (2005).

11. M. Kodama, T. Matsushita, \& S. Kojima, Jpn. J. Appl. Phys., 34, 2570 (1995).

12. Y. Matsuda, Y. Fukawa, Y. Ike, M. Kodama, \& S. Kojima, J. Phys. Soc. Jpn., 77, 084602. (2008).

13. M. Kodama, K. Iizuka, M. Miyashita, N. Nagai, W. Clarida, S. A. Feller \& M. Affatigato, Eur. J. Glass Sci. Technol. A, 44, 50 (2003).

14. Y. Fukawa, Y. Matsuda, Y. Ike, M. Kodama, and S. Kojima, J. Appl. Phys. Jpn., 47, 3833 (2008). 
15. G. S. Henderson, M. E. Fleet, A. C. A. 27, 269 (1991).

16. S. Mamiya, Y. Matsuda, Y. Fukawa, M. Kawashima \& S. Kojima, Eur. J. Glass Sci. Technol. B, 50, 321 (2009).

17. V. Rajendran, N. Palanivelu, P. Palanichamy, T. Jayakumar, Baldev Raj, B. K. Chaudhuri, J. Non-Cryst. Solids, 296, 39 (2001).

18. T. J. Kiczenski, C. Ma, E. Hammarsten, D. Wilderson, M. Affatigato, S. Feller, J. Non-Cryst. Solids, 272, 57 (2000). 


\section{Figure captions}

Table1. The chemical composition analysis of the $\mathrm{xK}_{2} \mathrm{O} \cdot(100-\mathrm{x}) \mathrm{GeO}_{2}$ glasses.

Fig. 1. Content dependence of Brillouin shift in $90^{\circ} \mathrm{A}$ scattering geometry.

Fig. 2. Content dependence of the longitudinal and the transverse sound velocity and Debye velocity.

Fig. 3. Content dependence of the elastic moduli.

Fig. 4. Content dependence of Debye temperatures and $\mathrm{T}_{\mathrm{g}}$. 